\title{
INCORPORATION OF 3D ELASTIC SEISMIC ATTRIBUTES IN THE DEFINITION OF GEOMETRIES AND DISTRIBUTION OF FACIES IN DEEP WATERS PROJECT IN ESPÍRITO SANTO BASIN
}

\author{
Danielle dos Santos Marques ${ }^{\star 1}$, Nara Gomes de Araújo Góis ${ }^{1}$ and Edgar Ambrosini Thedy ${ }^{1,}{ }^{1}$ Petrobras.
}

Copyright 2021, SBGf - Sociedade Brasileira de Geofísica.

This paper was prepared for presentation during the $17^{\text {th }}$ International Congress of the Brazilian Geophysical Society held in Rio de Janeiro, Brazil, 16-19 August 2021.

Contents of this paper were reviewed by the Technical Committee of the $17^{\text {th }}$ International Congress of the Brazilian Geophysical Society and do not necessarily represent any position of the SBGf, its officers or members. Electronic reproduction or storage of any part of this paper for commercial purposes without the written consent of the Brazilian Geophysical Society is prohibited.

\section{Summary}

The study is about an offshore exploratory area located in the southern portion of the Espírito Santo basin within a compressive tectonic context, formed by reservoirs of Campanian turbiditic sandstones. The reservoir presents a NE-SW depositional trend due to high geological complexity, represented by this compressive environment with a great effort transfer zone and intense salt tectonics, that changed the local physiography.

In this way, the reservoir is inserted in the context of amalgamated channels complex at the base, passing to discrete channels with overflows to the top of the reservoir.

The challenge, in the most of reservoir projects, is getting a good representation, in this case, of these turbiditic channels, with their different zones, in a geological model.

So, in this work, we propose the use of the 3D cube resulting from a geostatistical elastic inversion to guide, volumetrically, the distribution of facies in the geological model, instead of using the 2D maps, as usual.

\section{Results}

There is one well in this area and it found gas in almost the entire reservoir ( 160 meters) and a thin layer of oil at the base (approximately 6 meters).

By analyzing the Vp / Vs $x$ Ip graphs, it is realized that the elastic parameters are sensitive to lithology and fluid change, indicating the good applicability of deterministic and geostatistical elastic inversions.

The geostatistical inversion aims to produce multiple plausible representations of the reservoir, resulting in a model of distribution of properties (elastic, facies, lithological). Some inputs are provided like turbidite sand bodies maps which are generated using seismic attributes and populated with NTG values. So, one of the goals of this methodology is incorporating the geological knowledge of the area to guide the probabilistic process.

As a result, we have a $3 D$ cube of facies probability occurrence that is used directly in geological modeling. It implies in saving time in this process and getting a robust $3 \mathrm{D}$ distribution of the elements. The facies simulation model captures the bodies of sand that the geoestatistical volume indicates, which brings a high reliability to the final geological model.

This distribution of facies has a strong impact on VOIP estimative, in addition to the production curve itself, which depends on the quality of representation of the reservoir geometry in the model.

\section{Conclusions}

Since the geological knowledge had already been incorporated into the geostatistical inversion process, the 3D volume of sand probability proved to be relevant when elaborating the facies model. Therefore, the geostatistical inversion proved to be a very robust method to meet the expectations of generating a spatial distribution model of occurrence of sand, with a better representation of the existing uncertainties, since it assembles fundamental parameters such as conceptual geological model, seismic and its interpretation, well profiles and results of deterministic inversion.

It is important to highlight that this work methodology optimizes costs and processes, confirming the ideal treatment of risks and supporting the company's investment decision making. 